\title{
A Knowledge Based System for Supporting Sustainable Industrial Management in a Clothes Manufacturing Company based on a Data Fusion Model
}

\author{
G. G. Vieira ${ }^{1}$, M.L.R. Varela ${ }^{2}$, R. A. Ribeiro ${ }^{3}$ \\ ${ }^{1,2}$ Department of Production and Systems, School of Engineering, University of Minho, \\ Campus de Azurém, 4800-058 Guimarães, Portugal \\ ${ }^{3}$ UNINOVA - CA3, 2829-516 Caparica, Portugal \\ gaspar_vieira@hotmail.com, leonilde@dps.uminho.pt,rar@uninova.pt
}

\begin{abstract}
In this paper we propose a knowledge based system (KBS), based on smart objects and a data fusion model to support industrial management decision making applied to a clothes manufacturing enterprise. The management processes cover factory-production levels to higher decision-making levels. Therefore, the proposed KBS contributes to solving different kind of decision problems, including factory supervision, production planning and control, productivity management, real-time monitoring, and data acquisition and processing. The web access via different middleware devices and tools at different process levels, along with the use of integrated algorithms, decision methods, and smart objects, promote an optimized use of knowledge and resources. In this paper the proposed KBS is introduced and an example of its use is illustrated with an example of a clothes manufacturing resources selection, using the embedded dynamic multi-criteria fusion model.
\end{abstract}

Keywords: Knowledge based system, industrial management decision making, dynamic multi-criteria decision model, manufacturing resources selection.

\section{Introduction}

Nowadays, manufacturing enterprises are facing many challenges to respond to higher levels of production quality requirements, such as products quality requisites, manufacturing processes optimization and the manufacturing management processes itself, because globalization is forcing enterprises to promptly and accurately respond to requests arising from all over the world. An example is the necessity to accurately plan manufacturing resources usage, as the industrial manufacturing environment is no longer working isolated for satisfying its own manufacturing orders, but they also have to satisfy production needs from other outside orders. Therefore, industrial companies have to form strategic relationships with business partners to increase their responsiveness to market changes and to share resources more effectively and efficiently, through reliable decision support systems for supporting manufacturing management [1-4]. 
Manufacturing management, at its higher level, involves defining strategies to connect people, processes, data (information), knowledge and decision-making. Further, in the current context of globalised markets, big quantities of more or less complex data has to be acquired and processed, to accurately make decisions in a daily basis, considering not just in-door information but also out-door one. Therefore, it becomes of utmost importance and necessity to integrate technology and knowledge for enabling accurate and timely responses to market requests [5-12].

In this paper we propose a knowledge-based system (KBS) for supporting manufacturing management decision-making, which includes a dynamic multi-criteria decision-making model (DMCDM) and a Data Fusion algorithm (FIF) [13-16] to ensure taking in consideration today's spatial-temporal global environments.

Moreover, the proposed KBS is linked with a set of smart objects, for collecting data at the machines and factory level, along with appropriate middleware technology and tools for supporting appropriate data storage and processing, thus improving decisionmaking processes. The concept of "Smart Objects" is well known and comes back from the late 1990's [17]. The main focus of the concept is on modelling interactions of smart virtual objects with virtual humans, agents, in virtual worlds".

This paper is organized as follows. In section 2 an overview of dynamic decisionmaking and data fusion models is presented. Section 3 briefly describes the proposed KBS, including a general view of the integrated data acquisition and processing module, based on smart objects. Section 4, presents an industrial application example of the usage of the KBS for selecting manufacturing resources in a clothes manufacturing company. In section 5 a brief literature review about related work is presented, and finally, section 6 presents some conclusions and planned future work.

\section{Background Context}

In the literature, many interesting works can be found related to manufacturing management frameworks and approaches [1-12]. The research project in [1] addresses the emergence of interactive manufacturing management at three levels: sector, system and enabling technologies. More details about characteristics and capabilities of manufacturing frameworks will be further discussed on the description of the proposed KBS, section 3.

As mentioned above, the KB System includes an embedded Dynamic Multi-criteria Decision Making model and Data Fusion algorithm. Classical MCDM is a technique widely used for selection problems [18] [19-21] that assumes a fixed time frame where knowledge from past or future information is not employed to support more informed decisions.

The first step in the classical MCDM [18] is to identify the available alternatives, selecting relevant criteria to evaluate each alternative and develop the decision matrix based on the level satisfaction of each alternative for each criterion. This phase is usually called knowledge elicitation. The next phase is to aggregate the satisfaction values of criteria for each alternative to achieve a final per alternative (rating) so they can be ranked. Further, in the classic MCDM there is only one matrix reflecting the current status of the system, while in the Dynamic MCDM (DMCDM) model [15] at 
least two matrices must be considered, the historic matrix, which represents the situation in the past, and the current matrix, which represents the current status. At each period (time or iteration) the 2 matrices are combined and the result stored (updated historic data) for the next iteration. Details about the mathematical formulations for this dynamic decision making model can be seen in [13-15]. Here, we follow the idea from [14] of extending this dynamic model [15] with a "future knowledge matrix" representing the estimated future values for certain criteria to evaluate the alternatives of the current situation. The past status includes historical data and the future or predicted knowledge can be calculated either by using a forecasting model or using experts' knowledge. The future or predicted information could also be generated by negotiation and estimation [14]. In summary our approach will consider three different matrices: past, present and future, as suggested in [14].

To perform the calculations and obtain a final score of aggregating the three matrices we follow the data fusion process (FIF algorithm) described in [13] [16]. This data fusion process includes 5 steps: 1) normalize the criteria using fuzzification [8]; 2) filter uncertainty; 3) define criteria weights; 4) fusing information by aggregating criteria; 5) final ranking. The mathematical details of the combined models behind the five steps can be seen in [13] [14] [15].

\section{Proposed KBS and Integrated Technologies}

In this work we propose the integration of different manufacturing management functions, varying from the administration scope down to the operational level, passing through the production planning and control, as illustrated in Figure 1.

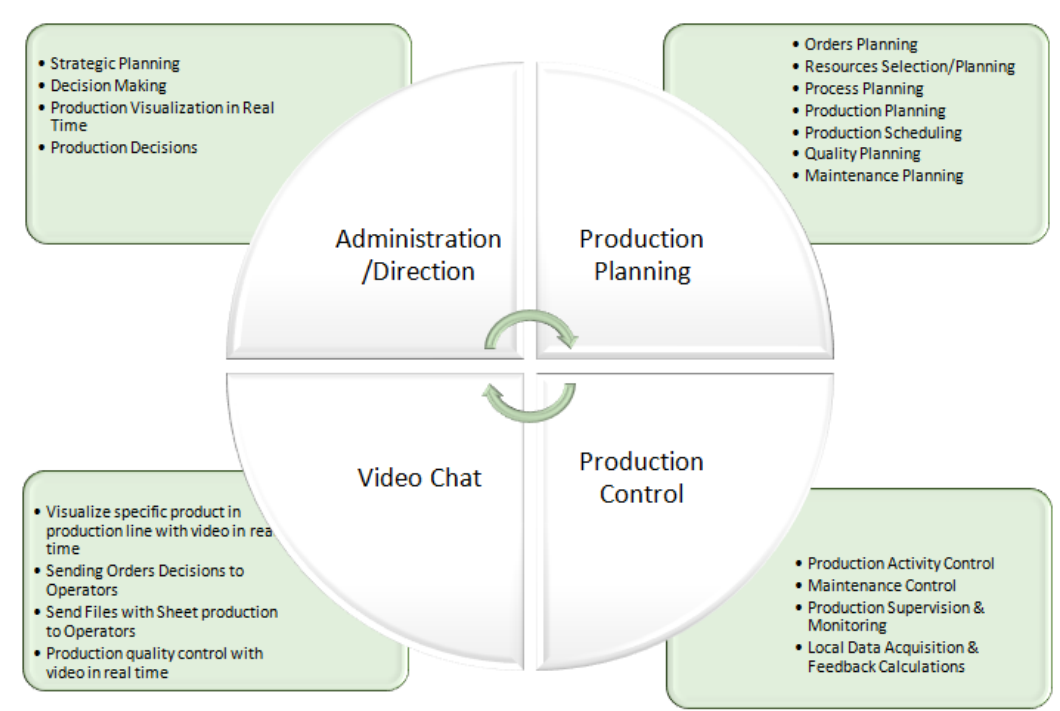

Fig. 1. Manufacturing management functions considered in the proposed KBS. 
To manage the complexity of the management functions in real decision making problems there are different types of strategies to simplify the problem [19-21]. The common strategy is to consider the situation time-independent and model the problem in a static situation. In this case, many important factors will be disregarded and in some cases it will result in erroneous decisions. Furthermore, most tactical and strategic decision in companies require some thought and time, sometimes even undergoing internal negotiations between departments, to reach a final decision, i.e. these types of decisions are spatial-temporal dependent.

Although at the operational level there is the capability of gathering real data from the shop floor, through smart objects, in terms of strategic and even tactic planning, it is of upmost importance to be able to consider manufacturing scenarios and strategies, based on future data/ information predictions, namely regarding information that arises from the outside of the factory, namely ad-hoc requests for using manufacturing resources or machines. These increasingly complex manufacturing management scenarios require using dynamic multi-criteria decision-making models, as many different kinds of information have to be considered. Therefore, in this work we consider a Dynamic Multi Criteria Decision Model (MCDM) [14] [15] along with a data fusion method [13] within the proposed KBS.

The proposed KBS and integrated technologies are mainly based on supervision equipment, data acquisition and processing devices and tools, including smart objects, as illustrated in Figure 2.

Regarding past and current data it can be either collected automatically, through the smart objects interacting with manufacturing resources or manually through MR managers. This data is further inserted in the KBS and processed and analysed through the underlying DSS, which integrated the MCDM implementation.

The matrices related to past, present and future data about MRs is updated each time some decision is made. Moreover, it is updated in a continuous, for instance daily and also in a real-time basis, regarding the information that is gathered automatically from manufacturing resources connected through the underlying network, within the local factory and the associated factories or outdoor collaborating businesses integrating the extended enterprise environment.

Future data can be predicted at different confidence levels through prevision models appropriate for each kind of information. Moreover, it can also be inserted manually, for instance, regarding new information received directly by local resource managers.

The three matrices regarding past, present and future information are associated through the MCDM in a dynamic and iterative way, as each iteration of this model, considers information arising from these three matrices, which is further merged and processed, based on the underlying data fusion method [13].

This KBS is intended to act as a "System-as-a-Service" (SaaS), integrating the services for real-time data acquisition from the equipment through the embedded intelligent information devices, which are smart objects in a clothes factory environment. The proposed KBS, should enable better decision-making support and enhance human-human and human-machine interactions, by means of the integration of information and its processing functions. 
Our illustrative example for the proposed integrated KBS, implements an application in the context of a clothes factory in Portugal. Figure 2 illustrates the general view about the principal entities and corresponding main interactions considered for data acquisition and processing within the clothes manufacturing environment, where the manufacturing resources in the production line of the clothes factory play a fundamental role. The Manufacturing Resources (MR) can be any provider of any service, machine tool type, human agents as service providers (designers, managers, machine operators, planners, schedulers, drivers, vendors, and others), computing resources, software, among others. The MR receives the orders from internal or external 'clients' and then negotiations are triggered (for example via chat, video conferencing, or email). After the approval of the order, the Resource establishes direct relationship with the client and executes the production order. As stated above, the Resource may give permission for the client to see the production order to be executed and may allow the client to control the use of distance (when the resource is a machine, a computer, or software), either from the control room, the $\mathrm{PC}$, or from a mobile device, and even remotely operated [12].

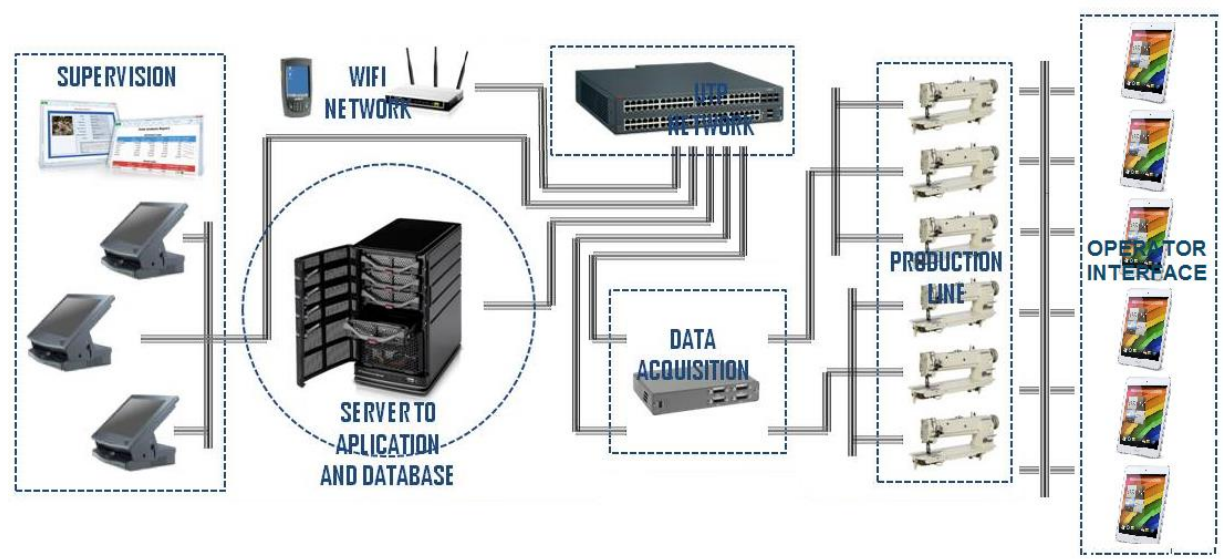

Fig. 2. Integrated technologies in a clothes factory environment.

In general, the integrated technologies include equipment for interactive monitoring systems and product design services that integrate four environments: 1) computer aided design, 2) product data repository with embedded system for decision making (for accessing all relevant data, such as current, historic or forecasted data as well as data analysis) from the equipment in use, and equipment operation services that integrate the following environments [9]:

1) Real-time equipment data that provides all relevant data, actual and historic as well as forecasted data and corresponding data analysis and suggestions, necessary for the production management;

2) Management environment information for monitoring, planning, scheduling and controlling production activities;

3) An interactive environment for supporting management - services;

4) A 'Cloud' infrastructure, necessary to provide: (a) infrastructure for the manufacturing system applications - of all three types of resources: material, manufacturing resources, information processing and other resources (i.e. 
computational resources), and knowledge resources - in the form of IaaS Infrastructure as a Service; (b) platform for the manufacturing system applications in the form of PaaS - Platform as a Service; (c) manufacturing system software 'business' applications in the form of SaaS - Software as a Service.

The KBS has been implemented in Visual Basic (VB) language to prototype the clothes application for this paper. The VB language enables easy development; as well as user friendly interfaces for data visualization and processing. Data and corresponding processing approaches and applications are managed in different places, which is of particularly importance in the context of a decentralized manufacturing scenario. For instance, if these globally distributed manufacturing environments have their own schedulers developed by different IT stakeholders; their schedules cannot be visualized by a common viewer without particular adapting programs. This actually causes a huge effort on a system's implementation, and both the cost and the risk of the system, which will be increased. Using interfaces developed through Visual Basic enables end users to have a personalized scheduling viewer, among other interfaces for supporting decision making, within a whole networked environment.

Figure 3 illustrates the system's interface for the clothes industrial application, which aims at enabling integrated and automatic processes and routines, along with corresponding data acquisition and processing, in a real-time basis.

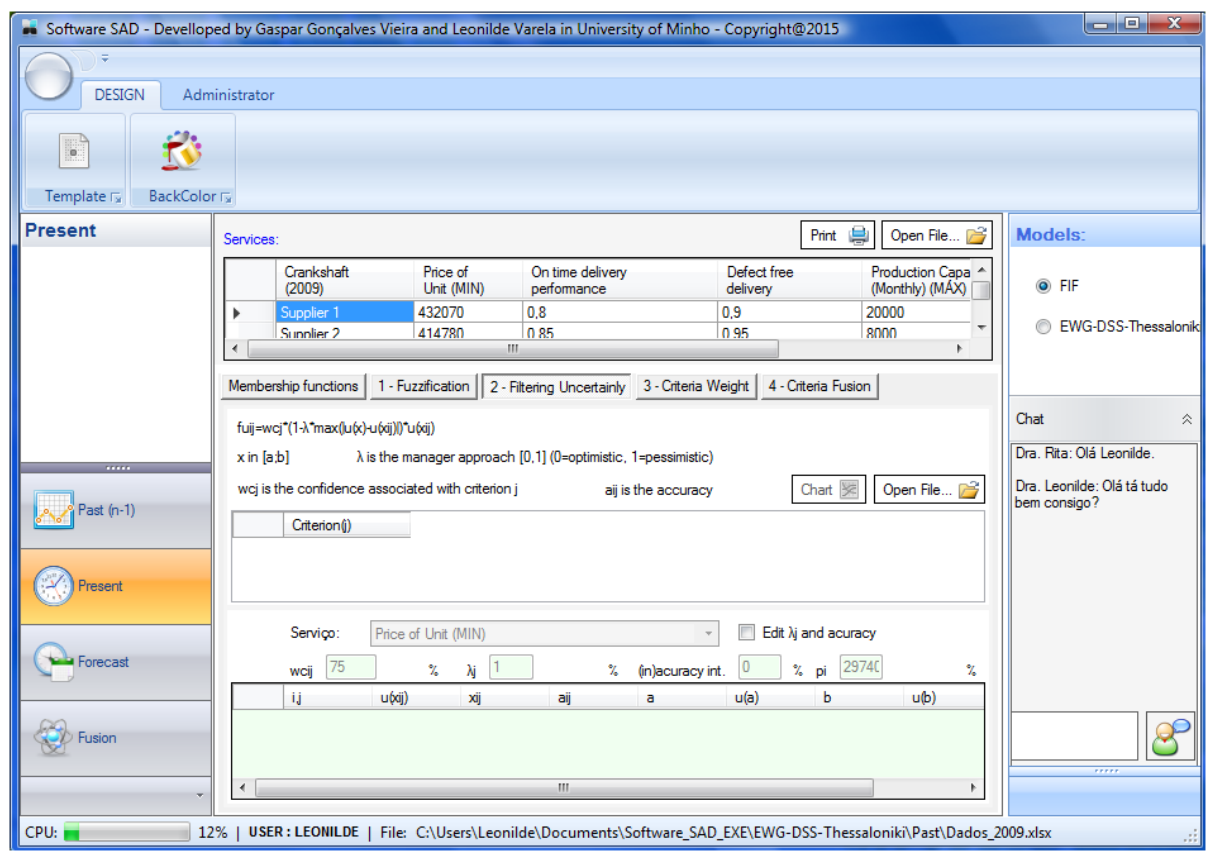

Fig. 3. KBS interface for supporting manufacturing management.

Specifically, Figure 3 depicts the interface for supporting manufacturing resources evaluation and selection, using the described dynamic multi criteria decision model 
(DMCDM) [14]. This interface provides flexibility for visualizing distributed plans everywhere through the Internet. Therefore, the proposed data representation and processing model can be seen as a general modelling schema, for problem data specification and processing for enabling to better supporting decisions at different decision levels intra and/or inter factories and stakeholders.

Moreover, one important aspect of the proposed KBS is its capability for enabling to acquire real data from the machines and other manufacturing resources, at the factory level, through smart objects technology, in a precisely and real-time basis [17], [22][25]. The smart objects have the capability to collect and store data in real time, to identify themselves and to make decisions, in a automatic and autonomous way, thus they play a crucial role in terms of real-time management functions, for supporting manufacturing, as they enable to update data to the second, instead of the traditional reports, which take sometimes days or even more time periods to enable to use updated data for manufacturing decision-making support.

The proposed KBS enables either to insert information about past, present and future data predictions regarding manual entries or directly in the database through automatic data insertion, namely data that is driven from the execution of the dynamic decision making model, once decisions are made. For this purpose the KBS includes some production rules that enable to filter relevant information, regarding positive decisions that are made, each time some manufacturing resource or business is selected for accomplishing a given manufacturing order. An illustrative example is provided in Figure 4 representing a production rule's pseudo-code from the KBS, which enables to store the data associated to MRs that have Production Costs (PC) that are half the value of a given product's price and which have a Quality Score (QS) higher than 70\% or a Number Of Complains (NOC) which is less than 4.

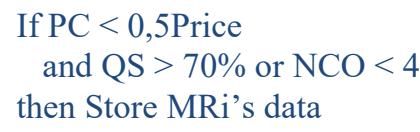

Fig. 4. Pseudo-code example of a production rule for automatic knowledge acquisition.

Through this kind of production rules the KBS is able to "learn" or update the past, present and future data matrices based on current selection of the manufacturing resources. This means that each time a MR (or business) is selected, and this decision is evaluated by the KBS, the KBS will automatically update its knowledge based on several distinct production rules, such as the one illustrated above, according to each specific context and requirements. This step is actually a very vital characteristic of the KBS, which enables it to capture data and support decision-making on a dynamic basis. Another important form through which the KBS can learn from the data is related to the manual data entries, for instance, regarding information that is gathered and introduced by system operators, each time new information arises, namely regarding data updates or previsions from stakeholders, for instance, each time future production and/or service prices' tables are announced or predicted by the manufacturing resources or services providers managers.

Furthermore, the smart objects are programmed with the proposed functions in order to enable to manage, in real time, machines and products, sending accurate, timely and 
reliable information, to workers responsible for production planning and control, machining, assembling and maintenance. The functions are included in the modules, where each one represents a type of data that a smart object can capture. Moreover, there is a higher level requirement about a need to distribute the whole data by the existing hierarchical levels in the enterprise, since each job title requires singular responsibilities and decision making, and the smart objects' architecture allows crossover through different technological levels.

\section{Industrial Application Example of the MCDM Module}

Here we present and illustrative example of selecting a manufacturing resource for producing a given product, which is an adaptation from the example in [14].

Let us consider six alternative manufacturing resources (MR1, MR2, ..., MR6) available from different factories, which can be used for producing a given set of products. Six criteria were chosen for both past and future data evaluation, and a different set of five criteria was chosen for present data evaluation, as shown in Table 2 and Table 1 , respectively.

The present criteria are the following: Production Cost (PC); Estimated Delivery Time (EDT); Lead Time (LT), which refers to the amount of days needed before the product processing starts (quoted); Remote Operation Capability (ROC), and Distinct Product Batches (DPB). The DPB criterion provides information about how flexible a given resource is, based on its processing potential, in terms of enabling different kind of products to be processed simultaneously in the same resource, at the same time or within the same production order. The historical and future information is evaluated by the six criteria: Production Cost, per hour (PC); On-time Delivery (OD); Daily Delay Penalization (DDP), based on the number of days orders were delayed; Quality Score (QS), about work delivered; Number of Complains per Order (NCO); and Portfolio Score (PS).

Table 1. Present data about candidate manufacturing resources

\begin{tabular}{|c|c|c|c|c|c|}
\hline $\begin{array}{c}\text { Manufacturing } \\
\text { Resources }\end{array}$ & $\begin{array}{c}\text { Production } \\
\text { Cost, PC }\end{array}$ & $\begin{array}{c}\text { Estimated } \\
\text { Delivery } \\
\text { Time, } \\
\text { EDT }\end{array}$ & $\begin{array}{l}\text { Lead } \\
\text { Time, } \\
\text { LT }\end{array}$ & $\begin{array}{c}\text { Remote } \\
\text { Operation } \\
\text { Capability, } \\
\text { ROC }\end{array}$ & $\begin{array}{c}\text { Distinct } \\
\text { Product } \\
\text { Batches, DPB }\end{array}$ \\
\hline Resource 1 - MR1 & 325 & 4 & 2 & 1 & 8 \\
\hline Resource 2 - MR2 & 560 & 3 & 3 & 0,95 & 7 \\
\hline Resource 3 - MR3 & 450 & 5 & 2 & 0,9 & 4 \\
\hline Resource 4 - MR4 & 375 & 2 & 4 & 1 & 6 \\
\hline Resource 5 - MR5 & 290 & 6 & 3 & 0,8 & 3 \\
\hline Resource 6 - MR6 & 340 & 6 & 2 & 0,9 & 7 \\
\hline
\end{tabular}


Table 2. Past and future data about candidate manufacturing resources *

\begin{tabular}{|c|c|c|c|c|c|c|c|c|c|c|c|c|}
\hline \multirow[t]{2}{*}{$\begin{array}{l}\text { Manufacturing } \\
\text { Resources }\end{array}$} & \multicolumn{2}{|c|}{$\begin{array}{l}\text { Production } \\
\text { Cost, PC }\end{array}$} & \multicolumn{2}{|c|}{$\begin{array}{c}\text { On-time } \\
\text { Delivery, } \\
\text { OD }\end{array}$} & \multicolumn{2}{|c|}{$\begin{array}{c}\text { Daily Delay } \\
\text { Penalization, } \\
\text { DDP }\end{array}$} & \multicolumn{2}{|c|}{$\begin{array}{c}\text { Quality } \\
\text { Score, QS }\end{array}$} & \multicolumn{2}{|c|}{$\begin{array}{c}\text { Number of } \\
\text { Complains } \\
\text { per Order, } \\
\text { NCO }\end{array}$} & \multicolumn{2}{|c|}{$\begin{array}{l}\text { Portfolio } \\
\text { Score, PS }\end{array}$} \\
\hline & past & future & past & future & past & future & past & future & past & future & past & future \\
\hline MR1 & 60 & 0,95 & 10 & 0,85 & 2 & 0,9 & 60 & 0,95 & 10 & 0,85 & 2 & 0,9 \\
\hline MR2 & 55 & 0,85 & 8 & 0,95 & 1 & 0,9 & 55 & 0,85 & 8 & 0,95 & 1 & 0,9 \\
\hline MR3 & 45 & 0,9 & 4 & 0,96 & 1 & 0,85 & 45 & 0,9 & 4 & 0,96 & 1 & 0,85 \\
\hline MR4 & 60 & 0,75 & 12 & 0,9 & 3 & 0,95 & 60 & 0,75 & 12 & 0,9 & 3 & 0,95 \\
\hline MR5 & 65 & 0,9 & 16 & 0,98 & 1 & 0,95 & 65 & 0,9 & 16 & 0,98 & 1 & 0,95 \\
\hline MR6 & & & & & & & & & & & & \\
\hline
\end{tabular}

* there is no past data for MR6 and therefore no future data also.

Using the values associated with each criterion for the three types of matrices (past, present and future) we performed the data fusion process with FIF algorithm [13], described in section 2 (see also the steps in the interface, Figure 3): 1) normalize the criteria using fuzzification; 2) filter uncertainty; 3) define criteria weights; 4) fusing information by aggregating criteria; 5) final ranking. Illustrating, Table 4 displays the results obtained for the historical matrix by performing the initial data preparation process.

Table 3. Normalized historical data with corresponding relative importance*

\begin{tabular}{|c|c|c|c|c|c|c|c|c|c|c|c|c|}
\hline Criterion & \multicolumn{2}{|c|}{$\mathrm{PC}$} & \multicolumn{2}{|c|}{ OD } & \multicolumn{2}{|c|}{ DDP } & \multicolumn{2}{|c|}{ QS } & \multicolumn{2}{|c|}{$\mathrm{NCO}$} & \multicolumn{2}{|c|}{ PS } \\
\hline \multirow[t]{2}{*}{ Weights } & fuij & $L(f u i j)$ & fuij & $L(f u i j)$ & fuij & $L(f u i j)$ & fuij & $L(f u i j)$ & fuij & $L(f u i j)$ & fuij & $L$ (fuij) \\
\hline & \multicolumn{2}{|c|}{$V I$} & \multicolumn{2}{|c|}{$I$} & \multicolumn{2}{|c|}{$I$} & \multicolumn{2}{|c|}{$A v$} & \multicolumn{2}{|c|}{$I$} & \multicolumn{2}{|c|}{$A v$} \\
\hline MR1 & 0,25 & 0,699 & 0,9 & 0,96 & 0,455 & 0,781 & 0 & 0,479 & 0 & 0,479 & 0,248 & 0,489 \\
\hline MR2 & 0,5 & 0,799 & 0,412 & 0,764 & 0,612 & 0,844 & 0,558 & 0,658 & 0,2 & 0,543 & 0,248 & 0,489 \\
\hline MR3 & 1 & 1 & 0,614 & 0,845 & 0,95 & 0,98 & 0,613 & 0,676 & 0,2 & 0,543 & 0 & 0,419 \\
\hline MR4 & 0,25 & 0,699 & 0 & 0,599 & 0,301 & 0,719 & 0,282 & 0,569 & 0 & 0,479 & 0,9 & 0,672 \\
\hline MR5 & 0 & 0,599 & 0,614 & 0,845 & 0 & 0,599 & 0,85 & 0,752 & 0,2 & 0,543 & 0,9 & 0,672 \\
\hline MR6 & & & & & & & & & & & & \\
\hline
\end{tabular}

* Legend of Table 3: (a) fuij are the normalized and filtered values from Table 2 for each criteria (step 1 and 2 of FIF algorithm); (b) L(fuij)) - are the criteria relative importance (Step 3 of FIF), which depend on the satisfaction level of the criteria and on the assigned relative importance (see $3^{\text {rd }}$ line on Table 3very important (VI); important (I); Average importance (Av)). For details on how to calculate Table 3 values see [13],[14].

After normalizing, filtering and determining the relative importance for each criterion we can calculate the rating for each criteria, per alternative. Illustrating, to determine the rating for criteria PC of alternative MR1 with past/historical information from Table 3 we have:

a) first we get the rating for each criterion, such as exemplified for PC:

$R(P C): 0.25 * 0.699 / 3.887=0.045$

where,

$\operatorname{Sum}(L($ fuij $))=0.699+0.960+0.781+0.479+0.479+0.489=3.887$ 
b) second we calculate the rating for alternative MR1,

$$
R(M R 1)=0.045+0.2223+0.0914+0+0+0.0312=0.389
$$

After obtaining the ratings for each matrix, past, present and future, the dynamic spatial-temporal process can be used [13], [14] for obtaining the final rating for all candidate businesses at time $t$ by aggregating the three matrices. Table 4 illustrates the final rating of the dynamic process using, again, the weighted average aggregation with weighting functions [13] where the relative weights depend on the values satisfaction. The last column of Table 4 contains the final vector ratings for all candidate alternatives.

Table 4. Final ratings

\begin{tabular}{|c|c|c|c|c|c|c|c|}
\hline \multirow{2}{*}{$\begin{array}{l}\text { Manufacturing } \\
\text { Resource }\end{array}$} & \multicolumn{2}{|c|}{ Historical } & \multicolumn{2}{|c|}{ Present } & \multicolumn{2}{|c|}{ Future } & \multirow{2}{*}{$\begin{array}{l}\text { Final } \\
\text { rating }\end{array}$} \\
\hline & rating & $\begin{array}{l}\text { Weight } \\
\text { (I) }\end{array}$ & rating & $\begin{array}{l}\text { Weight } \\
\text { (VI) }\end{array}$ & rating & $\begin{array}{c}\text { Weight } \\
(A v)\end{array}$ & \\
\hline MR1 & 0,39 & 0,68 & 0,891 & 0,946 & 0,318 & 0,581 & 0,586 \\
\hline MR2 & 0,446 & 0,7 & 0,604 & 0,802 & 0,529 & 0,649 & $\mathbf{0 , 5 3}$ \\
\hline MR3 & 0,666 & 0,779 & 0,377 & 0,689 & 0,421 & 0,614 & 0,498 \\
\hline MR4 & 0,309 & 0,651 & 0,76 & 0,88 & 0,361 & 0,595 & $\mathbf{0 , 5 1}$ \\
\hline MR5 & 0,467 & 0,707 & 0,391 & 0,696 & 0,301 & 0,576 & 0,392 \\
\hline MR6 & 0 & 0,539 & 0,564 & 0,782 & 0 & 0,479 & 0,245 \\
\hline
\end{tabular}

Illustrating again for MR1, we determined the final score for each alternative using the dynamic model [13], [14] as follows,

$\operatorname{Sum}(L(u i j))=0.680+0.946+0.581=2.207$

Final score $=(0.680 / 2.207) * 0.390+(0.946 / 2.207) * 0.891+(0.581 / 2.207) * 0.318=$ $=0.12+0.382+0.0837=0.586$

After analysing the final scores obtained we can conclude that the products processing task should be assigned to the top ranked candidate manufacturing resource, "MR1", which displayed a final score of 0.586 .

\section{Related work and contribution}

In recent years, the rapid development in information technology and in particular regarding internet technology turns the complex interaction and interoperability problems quite simpler to solve. However, despite the many advantages arising from these recent technologies, there are still some issues that have to be overcome particularly regarding collaboration levels integration and corresponding information processing and decision-making support that has to be assured within distributed manufacturing networks, which require dynamic and real-time decision making capabilities. Therefore, it is necessary to propose and develop frameworks, 
architectures, and methods by combining them with the current collaborative network models to compete within the global market scenario.

In this direction, during the last decade, the rapid development of NICT (New Information and Communication Technologies), with special emphasis on the advancement of RFID technology, Bluetooth and Wi-Fi, allowed the development of new production systems tools with traceability, visibility and interoperability in real time facilitating planning and shop floor control [26-28]. This means that any manual activity, time consuming and prone to errors associated with data collection and processing is able to be reduced or even eliminated, since the capture and processing of information that takes place in real time, thus allowing a more rapid and accurate decision-making [26].

The concept of smart object plays a key role in this new generation production systems to explore the integration of physical objects with the technologies outlined above, in order to "acquire" a set of said "smart" properties.

That is, a product throughout the supply chain, is not only a physical good, but a key element in the information infrastructure, through interaction with other products, processes and stakeholders in this same chain. To offer companies a new paradigm of interaction with their products and manufacturing resources are expected significant gains in operational efficiency. Automatic monitoring and context perception enable one best performance of information systems, such as Supply Chain Management, the Enterprise Resource Planning and Warehouse Management Systems, as they are no longer fed by outdated information [21].

Frequently, the major problem associated with the interaction of the smart objects is that sometimes they use different communication protocols, raising problems of compatibility and synchronization of information [27].

There is a variety of interesting and more or less closely related decision-making tools available, for instance [26-28]. Although, our proposed decision-making system provides some extensions, regarding the integration of several distinct technologies, among which are also included, smart objects for local and remote data collection and processing directly from manufacturing resources or managers. Moreover, our proposed system is based on a dynamic MCDM, which enables to integrate and process past, present and future information, regarding a variable set of criteria, according to each particular request arising in the context of different manufacturing management decision levels and requests as described before through an example of use occurring in the context of a clothes manufacturing environment where the system is being implemented and tested.

\section{Conclusion}

This paper described a knowledge based system (KBS) for supporting industrial management decision making in a clothes factory. The proposed KBS integrates a set of technologies which enable to directly interact with machines and equipment in the shop floor for data acquisition and its subsequent processing for supporting industrial management decision making (IMDM). One important tool for this IMDM is a module that integrates a combined dynamic multi criteria decision model (DMCDM) and data 
fusion model (FIF algorithm) for supporting evaluation and selection of manufacturing resources (MR), from a pool of MRs put available either locally in the clothes factory shop floor or in another associated factory. An illustrative example of the application of the MCDM plus FIF was presented in the paper for clarifying its utility for the proposed KBS.

Moreover, the effectiveness of the integrated technologies and approaches was briefly described and illustrated through the application example provided, namely regarding smart objects, which play a very important role in the proposed KBS, namely at the shop floor level for the data acquisition and local data processing. An important aspect of the KBS is that data can be generated and visualized by computers and other devices, including the smart objects, in appropriate and distinct ways and it is also important to notice that the data representation schema is general for distinct kind of manufacturing requisites.

For being able to fully implement the overall characteristics of the proposed KBS, there is still some need of further work to implement additional functionalities, as for instance for fully implementing the data fusion algorithm (FIF) and then tests and validation on the complete KBS also have to further continuing to take place.

Acknowledgments. This work was supported by FCT "Fundação para a Ciência e a Tecnologia" under the program: PEST2015-2020, reference: UID/CEC/00319/2013.

\section{References}

1. Yongjiang SHI Don FLEET Mike Gregory, "Global Manufacturing Virtual Network (GMVN): A Revisiting of the Concept of After Three Years Fieldwork". Journal of Systems Science and Systems Engineering, (12)4, 432-448, December, 2003.

2. Varela, M.L.R., Putnik, G.D., Cruz-Cunha, M.M., Web-based technologies integration for distributed manufacturing scheduling in a virtual enterprise (2012). International Journal of Web Portals 4(2), 19-34 (doi: 10.4018/jwp.2012040102).

3. Arrais-Castro, A., Varela, M.L.R., Putnik, G.D., Ribeiro, R.A. (2012), Collaborative network platform for multi-site production, Lecture Notes in Business Information Processing 121 LNBIP, 1-13. doi: 10.1007/978-3-642-32191-7 1.

4. Carvalho, J. B. Varela, M. L. R. Putnik, G. D., Hernández, J. E. Ribeiro, R. A. A web-based decision support system for supply chain operations management - Towards an integrated Framework. In: Decision Support Systems II - Recent Developments Applied to DSS Network Environments. J. E. Hernández, S. Liu, B. Delibašic, P. Zarate, F. Dargam, R. Ribeiro (Editors).Lecture Notes in Business Information Processing (LNBIP) Springer-Verlag, Vol. 184. pp. 104-117 (2014) DOI: 10.1007/978-3-319-11364-7_10.

5. Jae Yeol Lee. Kwangsoo Kim. A distributed product development architecture for engineering collaborations across ubiquitous virtual enterprises. Springer-Verlag London Limited 2006.

6. O. Appleton, et al. (2010). The next-generation ARC middleware, Ann. Telecommun. 65:771776 .

7. Varela, L. R., \& Ribeiro, R. A. (2003). Evaluation of Simulated Annealing to solve fuzzy optimization problems. Journal of Intelligent and Fuzzy Systems, (14), 59-71.

8. Goran Putnik, "Advanced Manufacturing Systems and Enterprises: Cloud and Ubiquitous Manufacturing and an Architecture". Journal of Applied Engineering Science 10(2012)3, 229, 127-134. 
9. Goran Putnik (2012), Advanced Manufacturing Systems and Enterprises: Cloud and Ubiquitous Manufacturing Architecture, Journal of Applied Engineering Science 10(2012)3, pp. 127-229. (doi:10.5937/jaes10-2511).

10. Cunha, Maria Manuela, Putnik, Goran D. (2008) "Market of Resources as a Knowledge Management Enabler in VE." In Knowledge Management: Concepts, Methodologies, Tools, and Applications, ed. Murray E. Jennex, 2699-2711.

11. G. D. Putnik, H. Castro, L. Ferreira, R. Barbosa, G. Vieira, C. Alves, V. Shah, Z. Putnik, M. Cunha, L. Varela, "Advanced manufacturing Systems and Enterprises - Towards Ubiquitous and Cloud Manufacturing", University of Minho, School of Engineering, LabVE, 2012.

12. R. A. Ribeiro, A. Falcão, A. Mora, J. M. Fonseca (2013) FIF: A Fuzzy information fusion algorithm based on multi-criteria decision making, Knowledge-Based Systems Journal 58: 23-32 DOI: http://dx.doi.org/10.1016/j.knosys.2013.08.032.

13. Jassbi, J. J., Ribeiro, R. A., \& Varela, L.R. (2014). Dynamic MCDM with Future Knowledge for Supplier Selection, Journal of Decision Systems, pp. 232-248, Taylor \& Francis, (http://dx.doi.org/10.1080/12460125.2014.886850).

14. A. D. Mora, A. J. Falcão, L. Miranda, R. A. Ribeiro, and J.M. Fonseca. A Fuzzy Multicriteria Approach for Data Fusion, In: Multisensor Data Fusion: From Algorithms and Architectural Design to Applications, Edited by Hassen Fourati, Chapter 7, CRC Press 2016, ISBN: 978-1-48226374-9, pp109-123.

15. G. Campanella and R. A. Ribeiro A Framework for dynamic multiple criteria decision making. Decision Support Systems, Volume 52, Issue 1, December 2011, Pages 52-60. DOI: http://dx.doi.org/10.1016/j.dss.2011.05.003.

16. Angels, R. (2005). RFID technologies: supply-chain applications and implementation issues. Information Systems Management, 22(1), 51-65.

17. Ng, S.T., \& Skitmore, R.M. (1995). CP-DSS: decision support system for contractor prequalification. Civil Engineering Systems: Decision Making Problem Solving 12 (2), 133-160.

18. E. Triantaphyllou, Multiple Criteria Decision Making Methods: A Comparative Study. Kluwer Academic Publishers, 2000.

19. J. Figueira, S. Greco, and M. Ehrgott, Multiple Criteria Decision Analysis: State of the Art Surveys. International Series in Operations Research \& Management Science, Springer 2005. vol 78.

20. De Boer, L., Labro, E., \& Morlacchi, P. (2001). A Review of Methods Supporting Supplier Selection. Journal of Purchasing and Supply Management, 7 (2). pp. 75-89. ISSN 1478-4092.

21. Bajic, E. (2009). A service-based methodology for RFID-smart objects interactions in supply chain. International Journal of Multimedia and Ubiquitous Engineering, 4(3), 37-54.

22. Beigl, M., and Gellersen, H. (2003). Smart-its: An embedded platform for smart objects. Proceedings of the Smart Objects Conference 2003 (sOc).

23. Huang, G.Q., Zhang, Y., Chen, X., Newman, S.T. (2008a). RFID-based wireless manufacturing for walking-worker assembly islands with fixed-position layouts. Robotics and Computer Integrated Manufacturing, 23(4), 469-477.

24. Zhekun, L. Gadh, R., and Prabhu, B. (2004). Applications of RFID technology and smart parts in manufacturing. Proceedings of the ASME 2004 International Design Enginnering Technical Conference and Computers and Information in Engineering Conference, 2004.

25. Kallman, Marcelo; Daniel Thalmann (1998). "Modeling Objects for Interaction Tasks". Springer. pp. 73-86.

26. Huang, G. Q., Zhang, Y., \& Jiang, P. (2008b). RFID-based wireless manufacturing for real time management of job shop WIP inventories. The International Journal of Advanced Manufacturing Technology, 36(7-8), 752-764.

27. Zhang, Y., Huang, G. Q., Qu, T., Ho, O., \& Sun, S. (2011). Agent-based smart objects management system for real-time ubiquitous manufacturing. Robotics and Computer- Integrated Manufacturing, 27(3), 538-549.

28. Zhang, Y., Huang, G. Q., Qu, T., \& Sun, S. (2013). Real-Time Work-in-Progress Management for Ubiquitous Manufacturing Environment Cloud Manufacturing (pp. 193-216): Springer. 